\title{
Convocando a Gramsci en América Latina. A propósito de un punto de convergencia en la teoría social en la Argentina contemporánea: Silvio Frondizi y José Aricó*
}

\author{
Juan Jorge Barbero ${ }^{* *}$
}

\begin{abstract}
Resumen
Moviéndonos en la dimensión disciplinar de la sociología política, articularemos en este trabajo ciertos aportes que entre las décadas de 1960 y 1990 esgrimieron los marxistas críticos argentinos Silvio Frondizi y José Aricó. A modo de hipótesis, consideramos que estos aportes pueden ser productivamente vinculados a las temáticas de la "traducibilidad de los lenguajes científicos y filosóficos" y del "constituyentismo", tratados por Antonio Gramsci en distintos momentos de su trayectoria político-intelectual pero fundamentalmente en sus ya míticos Cuadernos de la cárcel. En el lapso que va de la Revolución Cubana de 1959 a las transiciones a la democracia en América latina en los últimos decenios del siglo XX, lo expuesto por Frondizi y Aricó apunta a desarrollar todo el potencial de la cuestión de la soberanía popular, estructurando así una promesa aún muy débilmente considerada tanto en la cultura como en la política.

Palabras clave: Traducibilidad de los lenguajes, constituyentismo, soberanía popular, municipio, ciencia política.
\end{abstract}

\begin{abstract}
Moving to the discipline of political sociology, we will articulate certain contributions of the critical Argentine Marxists, Silvio Frondizi and José Aricó, whose primary writings spanned the decades of 1960s to the 1990 s.
\end{abstract}

\footnotetext{
* Recibido: noviembre 2017. Aceptado: diciembre 2017.

*** Universidad Nacional de La Plata. Buenos Aires, Argentina. Email: juanjorgebarbero@hotmail.com
} 
As a hypothesis, we will consider that these contributions can be productively linked to the themes of the "translatability of scientific and philosophical languages" and of "constitutionalism", referred to by Antonio Gramsci at different moments of his political-intellectual trajectory, but fundamentally in his already legendary Prison Notebooks.

In the period from the Cuban Revolution of 1959 to the transitions to democracy in Latin America in the last decades of the 20th century, what Frondizi and Aricó have set out to develop is the full potential of the notion of popular sovereignty.

Keywords: Translatability of languages, constitutionalism, popular sovereignty, municipality, politics science.

Dejándonos orientar por piezas del Gramsci de los Cuadernos de la cárcel (por ejemplo, por las notas 81 y 162 del Cuaderno 6, la 2 del Cuaderno 7 y la 55 del Cuaderno 8) (Gramsci, 2000), en las que las temáticas de la "traducibilidad de los lenguajes científicos y filosóficos" y del "Constituyentismo" sobresalen ( $\sin$ omitir otros aspectos que se presentan afines y complementarios con esas temáticas), en este trabajo abordamos aquello que observamos, en términos de hipótesis, como un estimulante punto de convergencia entre ciertos escritos de los intelectuales argentinos Silvio Frondizi (1907-1974) y José Aricó (1931-1991), dándose particularmente esta convergencia en los criterios con que ambos estudiosos buscan producir transformaciones profundas de la cultura socialista y de las condiciones histórico-sociales en el contexto argentino/latinoamericano de su tiempo, pretendiendo tomar estas transformaciones la forma de una imbricación entre peculiares concepciones al interior de las tradiciones democrática y socialista.

Para el desarrollo de nuestra hipótesis, estimamos productivo fijar un vínculo estructural entre el punto de convergencia de Frondizi y Aricó y el tramo de la nota 4 del cuaderno 15 de los Cuadernos de la cárcel, en donde Gramsci, dando pautas para colocarse en el punto neurálgico de la ciencia política, enfatiza que es preciso decir que los primeros en ser olvidados son justamente los primeros elementos, las cosas más elementales; por lo demás, éstas, repitiéndose en infinidad de ocasiones, acaban deviniendo pilares de la política y de cualquier acción colectiva. Y el primer elemento es que existen realmente gobernados y gobernantes, dirigentes y dirigidos. Toda la ciencia y el arte de la política tienen su base en este hecho primordial, irreductible (en 
el marco, ciertamente, de determinadas condiciones generales). Los orígenes de este hecho son un problema en sí mismo y en sí mismo deberá ser estudiado (al menos, podrá y deberá estudiarse cómo atenuar y hacer desaparecer el hecho, cambiando aquellas condiciones identificables como actuantes en este sentido), pero permanece el hecho de la existencia de dirigentes y dirigidos, de gobernantes y gobernados.

Y hace desprender de este criterio el siguiente interrogante:

[...] al formar dirigentes es fundamental la premisa: ¿se quiere que existan siempre gobernados y gobernantes, o bien se quieren crear las condiciones en las que la necesidad de existencia de esta división desaparezca?, es decir, ¿se parte de la premisa de la perpetua división del género humano o se cree que ésta es sólo un hecho histórico, que responde a ciertas condiciones? (Gramsci, 2000: 175-176).

Este fragmento gramsciano puede muy bien representar la base de sustentación de nuestro anclaje en los análisis que Frondizi expusiera (en las décadas de 1960 y 1970) en relación a la revolución cubana y a variados aspectos de la historia argentina, y en los que Aricó desplegara (entre 1976 y 1991) en relación a la temática de la "transición a la democracia". En los trabajos de estos destacados exponentes del "marxismo crítico" argentino, el punto de convergencia gira en torno al señalamiento de potencialidades del territorio municipal como instancia necesaria (de ningún modo suficiente, pero necesaria) de construcción hegemónica socialista, de despegue de un proceso de reconfiguración laica e inmanentista (para usar palabras y sentido gramscianos) de la soberanía popular, pretendiendo alcanzar el contenido humanista de un "desarrollo integral de la personalidad humana".

\section{2}

Para Frondizi, en Argentina el golpe militar de Onganía, de junio de 1966, evidenciará "consecuencias tremendas: los tres comandantes militares se declararon titulares del poder constituyente, mostrando por primera vez en el país una verdad en forma descarnada: la de que el pueblo nunca fue el titular del poder constituyente" (Frondizi, 2014: 31). Finalmente, ni el radicalismo ni el peronismo habían dado a las clases populares el poder constituyente, descansando aquí parte central del origen de la larga crisis política que Frondizi viene diagnosticando desde la primera mitad de la década de 1940, entendida como crisis estructural del Estado burgués-liberal ante el avance de la sociedad de masas. En los años 1956/57, en el contexto de la proyectada re- 
forma constitucional en la Argentina, cuando "la derogación por decreto, por el gobierno de facto, de la constitución de 1949, [...] ha colocado al país en un verdadero estado de asamblea", cree que "la próxima convocatoria de una convención constituyente ofrece una excelente oportunidad para propugnar reformas de fondo, que la pongan a tono [a la Constitución] con el progreso alcanzado por el mundo y el país en el terreno económico-social y político" (Frondizi, 2014: 23). En la Argentina de 1956/57, Frondizi veía que la crisis del Estado burgués-liberal había desembocado en un desembozado proceso de desintegración nacional, debiendo el desarrollo de la reforma constitucional:

$[\ldots]$ en lo social y político, $[\ldots]$ facilitar el ascenso del pueblo al control del Estado. La primera reforma que en este sentido es necesario realizar es derogar el artículo 22 de la Constitución, que establece, como es sabido, que el pueblo no delibera ni gobierna sino por intermedio de sus representantes. Entiendo, por el contrario, que el pueblo debe deliberar y gobernar por sí mismo. [...] Esta debe ser la regla general; y la excepción, la delegación de poderes (Frondizi, 2014: 24).

El advenimiento de la Revolución cubana de 1959 ahondará en Frondizi su vocación por superar el estancamiento en cuestiones de soberanía en la realidad latinoamericana. Desde 1946, Frondizi consideraba que la flamante formación del Banco Mundial y el Fondo Monetario Internacional era síntoma de una nueva instancia de desenvolvimiento de un capitalismo que se revolucionaba a sí mismo, con una lógica interna que lo orientaba tendencialmente hacia lo que muy creativa y tempranamente llamará "integración mundial capitalista". Estados Unidos devenía rector de esta nueva fase del capitalismo y la dinámica del Plan Marshall fortalecía su rol de "potencia integradora" (Frondizi, 2014: 13). En este nuevo marco de fuerzas internacionales debía reconquistar su lugar y reconfigurarse la siempre obstaculizada noción de soberanía popular, y es de sus estudios sobre la revolución cubana de 1959 de donde Frondizi desprende la siguiente idea, con la cual lleva adelante un ejercicio de traducción del lenguaje político: "Esperamos que esta experiencia se desarrolle también en nuestro país, a través de la lucha para afirmar la fundamental autonomía de las municipalidades. El movimiento de Córdoba así lo preanuncia" (Frondizi, 2014: 23).

Ante la ineludible exigencia de internacionalizar el oleaje revolucionario, no se debía copiar o calcar la modalidad revolucionaria cubana, sino traducir su lenguaje mediante el reconocimiento de las diferentes realidades nacionales latinoamericanas. De este modo, era el municipio el que podía erigirse en 
punto de partida para que el "estado de asamblea" en Argentina se canalizara hacia nuevas formas de intervención pública y fuera el resorte de una transformación social integral. Las energías populares del 17 de octubre de 1945 no habían encontrado en el país vías de sustanciación para sus más heréticas cualidades, mientras las intervenciones militares de 1955 y 1962 (sumadas al particular significado de la proscripción del peronismo) no hacían más que colocar en el centro de la escena, de manera a la vez violenta y grotesca, la "crisis de la democracia", dentro de la cual la burguesía nacional exponía en carne viva su caducidad histórica. Parafraseando a un Gramsci que a principios de los años sesenta ya ocupa un lugar en sus escritos (que se hará explícito a principios de 1963), Frondizi subraya que "el país se encuentra a mitad de camino entre un sistema que agoniza y otro nuevo que comienza a nacer. Ello produce la desaparición de pautas firmes y aceptadas para interpretar la realidad y guiar las conductas de individuos y grupos" (Frondizi, 2014: 168). En resumen, el país vivía una crisis de hegemonía. Para el Frondizi de la década de 1960, en la "caducidad de la burguesía nacional" no podía no concentrarse la crisis de la historia argentina en su globalidad, que había ido adquiriendo con progresiva y conflictiva firmeza, desde mediados del siglo XIX, la forma del "centralismo burocrático", producto de una conjugación de procesos de concentración económica, política y militar. De este modo, el proyecto de Frondizi anima un programa de reconstrucción nacional (de ningún modo nacionalista, en todo sentido universalista), con el legado federalista brindando una suerte de criterio general de proyección popular, tendiente a que "los pueblos argentinos" puedan darse mecanismos de autodeterminación, superadores del "centralismo burocrático" (Frondizi, 2014: 26). Pero el legado federalista se extrema hasta verse superado, creando con la noción de "autodeterminación popular" una nueva corriente de estudios en materia de derecho político y nuevas posibilidades prácticas de soberanía popular. Así, la pluma de Frondizi no puede ser más intensa ni estar más cargada de expectativas en la capacidad de iniciativa de las masas:

El hombre de pueblo ha debido reemplazar a la burocrática e incompetente acción municipal actual, con organizaciones populares que cubran, en los aspectos más urgentes, las necesidades locales de los barrios y villas. La labor de estas organizaciones populares, llamadas sociedades de fomento o vecinales, expresan -en uno de sus aspectos principales- nuestra confianza en el futuro del país. Es precisamente a través de organizaciones populares de este tipo -por supuesto que ampliando las esferas de su acción- en donde podremos hallar el mecanismo que permita al pueblo organizarse, luchar y dirigir. Partiendo del control de las organizaciones locales, de éstas al municipio, del 
municipio a las provincias y luego a toda la Nación, el hombre de pueblo, el trabajador, podrá ejercer efectivamente su papel de dirigente y lo hará en un régimen que, entonces sí, merecerá llamarse democrático (Frondizi, 2014: $160-61)$.

Todo ello en parte se apoya en una política general, en la que el uso del legado gramsciano queda al descubierto: "Debe impulsarse y dar dirección ordenada al ascenso de las masas y a la hegemonía de los trabajadores en la conducción de la economía, del Estado y de la vida social en su conjunto" (Frondizi, 2014: 160). De este modo, "autodeterminación popular y humana", "sociedades de fomento", "democracia auténtica", son sólo algunas de las expresiones que se tornan viables para Frondizi si logran insertarse en una serie virtuosa de círculos concéntricos, que obtengan su primera y más elemental articulación en la dimensión municipal y se muestren capaces de ampliar cada vez más "su esfera de acción", adquiriendo así un sentido acabado aquella rutilante idea, escrita al regreso de su viaje a Cuba: "Ha llegado el momento del triunfo de la concepción roussoniana, a través de la praxis marxista" (Frondizi, 2014: 27).

Tomamos al editorial del primer número de la revista Controversia, editado desde México en octubre de 1979, como punto de arranque para evaluar las transformaciones que este intelectual cordobés realiza en su itinerario de investigación, subrayando las profundas reconfiguraciones y reactualizaciones que, con ciertas precisiones, intentará dar a la cuestión de la hegemonía en el contexto latinoamericano, con especial acento en Argentina. El reconocimiento de "una derrota atroz" de las clases populares argentinas en el transcurso de la primera mitad de la década de 1970, "que no sólo es la consecuencia de la superioridad del enemigo sino de nuestra propia incapacidad para valorarlo, de la sobrevaloración de nuestras fuerzas, de nuestra manera de entender el país, de nuestra concepción de la política" (Vargas, 1979: 2), se incorpora al programa de un cambio morfológico de la cultura socialista, no resultando esto viable si se continua recorriendo "el camino de siempre, si no alcanzamos a comprender que es necesario discutir incluso aquellos supuestos que creemos adquiridos de una vez para siempre, para una teoría y práctica radicalmente transformadora de nuestra sociedad" (Vargas, 1979: 2). 
Para Aricó el destino de América Latina "se llama democracia", pero sin embargo lejos está de aceptar el contenido de las "transiciones a la democracia" que en el subcontinente se viene corporizando:

Cuando se afirma que los cambios son necesarios pero que es preciso esperar momentos de mayor tranquilidad para hacerlos, se supone que se puede alcanzar la 'tranquilidad' sin el cambio. En mi opinión ésta es una de las formas de soñar con los ojos abiertos, porque se afirma en una creencia que rechaza las lecciones de los hechos y desplaza a un futuro imprevisible una necesidad del presente. Es difícil imaginar la consolidación de un Estado de derecho en la Argentina sin introducir cambios en la estructura del Estado y de la sociedad que den respuestas a las demandas de intervención colectiva que desbordan las limitaciones y flaquezas de las instituciones del constitucionalismo liberal clásico (Aricó, 1986: 15).

Siguiendo esta lógica, ¿podría crearse, con la riqueza que ampliamente se le reconoce al criterio gramsciano de hegemonía, una combinación productiva entre las tradiciones democrática y socialista?, ¿podría el núcleo mismo del Estado de derecho verse penetrado por el torrente de aquella combinación y ser involucrado y transfigurado en un proceso de cambios estructurales? Ni las diferentes vertientes del liberalismo, ni el marxismo-leninismo, ni el populismo, ni la socialdemocracia pueden brindar respuestas satisfactorias a estas preguntas, y precisamente por razones tan contundentes como éstas nos encontramos, para Aricó, nada más y nada menos que ante una "crisis de civilización". En este sentido, en 1991, no dudará en decir que Argentina "ha cambiado, y no para bien, por supuesto", puesto que soporta "una crisis general y profunda que atraviesa a toda la sociedad, descompone tejidos sociales y culturales, degrada la política y estimula una atmósfera generalizada de renuncia a una proyectualidad fuerte y visible" (Aricó, 1991: 6) y sin embargo los estudios sociales no logran volar alto en relación a las primeras exigencias democráticas, tendiendo

[...] a analizar más lo que existe, lo ya dado, lo que finalmente ha acabado por imponerse, que las alternativas que en la realidad se presentaron para que pudieran imponerse procesos efectivos de democratización y socialización progresiva de las sociedades latinoamericanas. En definitiva, buena parte de la reflexión teórica e histórica estuvo dedicada más al análisis de los vencedores que a la indagación de las alternativas que no pudieron resolver en su favor los vencidos (Aricó, 1985: 4). 
Pero el esfuerzo de acentuada innovación que Aricó demanda a las corrientes críticas de los estudios sociales en las transiciones democráticas, de ningún modo niega el rescate de experiencias que, ubicadas en diferentes momentos de la Guerra Fría, aportaron elementos valiosos para la conquista de una integración dinámica entre democracia y socialismo. La innovación implica ejercicios de traducibilidad de experiencias políticas. Por ejemplo, por traumático que haya resultado el aplastamiento de determinadas experiencias en Europa del este, para Aricó es especialmente llamativo que:

[...] en toda esta discusión actual sobre democracia y socialismo, mientras se habló de muchas cosas, otras pasaron bastante ignoradas. Una de ellas es que la discusión más tensa, pero con enormes posibilidades de resolución positiva en el plano de la política, fue la que comprometió a socialistas y comunistas europeos -y no sólo a ellos, pues el 'browderismo' debe ser también colocado en este terreno- a fines de la segunda guerra mundial. En los años 1945-1947, los procesos de transición encarados en los países de Europa oriental partían de la unidad socialista y comunista (no organizativa, sino política y de objetivos), para proponerse la construcción de una democracia avanzada ('nueva democracia') con base en las reformas de estructuras y el pluralismo político [...] Rechazado el modelo soviético como único y excluyente, el método democrático aparecía como connatural al proceso de transición hacia una forma de sociedad autorregulada (Aricó, 1980: 15).

La "sociedad autorregulada" que esgrime Aricó se desprende directamente de la noción gramsciana de "sociedad regulada", como aquella instancia a la que se aspira desembocar luego de un proceso largo, de núcleo eminentemente dilemático, en el cual la actividad tanto de la sociedad política como de la sociedad civil se presentaría intensamente activa y en el que el complejo entramado de entrecruzamientos institucionales y sociales se iría desplegando junto a "un sistema de principios que afirma como objetivo del Estado su propio fin, su propia desaparición, o sea, la reabsorción de la sociedad política en la sociedad civil" (nota 127 del Cuaderno 5) (Gramsci, 2000: 346). Las experiencias frustradas de Europa oriental y la noción gramsciana de "sociedad regulada" son ensambladas por Aricó, al mismo tiempo que son señaladas las diferencias constitutivas entre las sociedades modernas en Europa y en América Latina, haciendo de este especial señalamiento el mismísimo fundamento histórico desde el cual proyectar una imbricación democrático-socialista inédita: 
La ruptura del orden constitucional español y portugués abrió el camino a una rápida fragmentación de la unidad territorial colonial y a la configuración de un agregado de estados formalmente soberanos que ya a mediados del siglo XIX había definido en gran parte sus fronteras nacionales. Sin embargo, resultaría imposible encontrar en este proceso de construcciones estatales algo idéntico o semejante a lo ocurrido en Europa, por ejemplo. La transformación de las nacionalidades en estados-naciones soberanos, característica dominante del siglo XIX en Europa, suponía como sujeto de la transformación a grupos humanos definidos previamente como 'nación', esto es, definidos por una historia con la que se sentían identificados por una cultura común, por una idéntica composición étnica $y$, cada vez más, por una lengua que reconocían como propia [...] El caso de América Latina ofrecía la singularidad de que, existiendo en parte, ninguna de las características distintivas del proceso europeo parecieron caracterizar al nuestro [...] Excepto el caso de Cuba -no por casualidad tan tardío-, donde por diversas razones la lucha independentista adquirió las características de un movimiento fuertemente enraizado en las masas populares, en el resto de los países latinoamericanos la construcción 'nacional' tendió a ser durante un largo período un hecho puramente estatal, protagonizado por minorías defensoras de intereses sectoriales y sin voluntad nacional, y caracterizado por la ilustrativa continuidad de las delimitaciones territoriales coloniales en los nuevos estados independientes [...] En América Latina, por tanto, el proceso aparecía invertido, de manera tal que la 'nación' no resultaba ser el devenir estado de una nacionalidad irredenta sino la construcción de una realidad inédita (Aricó, 1980b: 100).

De este modo, las "transiciones a la democracia" en la América Latina del último cuarto del siglo XX (en las que, para Aricó, la recuperación del pensamiento del peruano José Carlos Mariátegui debe insertarse estratégicamente) se vuelven el teatro de operaciones que, intentando impedir que el elemento popular sea cauterizado por las "instituciones del constitucionalismo liberal clásico", innoven con dispositivos institucionales portadores de un nuevo modo de gobernar, permitiendo que "los electores decidan sobre programas y personas", renovando las instituciones de representación y de delegación, hasta que la legitimación de los proyectos y de las construcciones políticas hagan del "consenso vinculante de los electores" (Aricó, 1990: 9) un aspecto clave de su base de sustentación.

Para Aricó, en este esfuerzo de imaginación sociológica que aspira a ir más allá de tradiciones políticas en pleno proceso de descomposición (que intenta, incluso, redescubrir ese espíritu experimental que ha sido patrimonio de las corrientes más osadas y creativas de la cultura socialista argentina) 
descansa otro punto decisivo de la reconfiguración de la conciencia colectiva, objetivo mayúsculo que deberá perseguir el futuro movimiento democrático-socialista latinoamericano:

Las ideas de soberanía popular, de federalismo, de regionalismo y poderes locales, de democracia directa y de municipalidades, de traspaso a la sociedad (y digo a la sociedad y no a las corporaciones) de funciones hoy asumidas por un Estado omnívoro, son estas ideas, y todas las otras que van en la misma dirección de una democracia social avanzada, las que debieran constituir el banco de prueba de las tradiciones intelectuales existentes, las que debieran fundirse en ese crisol de matrices que propugno. Mi preocupación por el marxismo se sitúa precisamente aquí. Por eso podría decirte en qué sentido cambió mi pensamiento en la última década. Si en un comienzo intenté pensar América Latina desde el marxismo, hoy me interesa mucho más ver qué efectos sobre una matriz ideológica tan perfecta, tan expresiva de una voluntad de progreso como fue y es el marxismo, tuvo una realidad irreductible a sus paradigmas. Más que el marxismo en sí, lo que hoy me interesa es lo que potencialmente encierran estos pueblos en su imaginario colectivo, en su memoria histórica, que pueda servir para la reinvención de América, de una América democrática y socialista (Aricó, 1986).

A modo de conclusión, consideramos que este punto de confluencia en las propuestas de Frondizi y Aricó atesora una verdadera "promesa" (Wright Mills, 1961: 23) en el terreno de la teoría social en la Argentina contemporánea, aún no registrada en todos sus términos ni en el campo cultural ni en el campo político. En el terreno temporalmente más acotado de las ciencias sociales en la Argentina pos-dictatorial, dos libros han tenido la virtud de abrir una vía de investigación para que esta promesa pueda ser conocida y evaluada: ellos son el del historiador Horacio Tarcus, titulado El marxismo olvidado en la Argentina: Silvio Frondizi y Milcíades Peña (Tarcus, 1996) y el del filósofo Raúl Burgos, titulado Los gramscianos argentinos. Cultura y política en la experiencia de Pasado y Presente (Burgos, 2004).

En todo caso, de una fusión entre el folleto de Frondizi "Bases y punto de partida para una solución popular”, de 1961 (Frondizi, 2014: 149), y el artículo de Aricó "Recuperar la memoria de las experiencias comunales: sobre el socialismo municipal" (Aricó, 1991b: 19), de 1991, podrá comprenderse que una valorización del territorio municipal conlleva al menos una doble y deci- 
siva implicancia: por un lado, la severa advertencia de no caer en la "pequeña política" que, como la sombra al cuerpo, acompaña al criterio municipalista; por otro lado, la creación de capacidades, en los ámbitos moleculares de la inteligencia popular, que posibiliten la identificación crítica de los múltiples hilos que conectan la vida del hombre común con la dinámica de un capitalismo mundialmente integrado. Dicho de otro modo, Frondizi y Aricó nos invitan a la creación de esa atmósfera de "gran política" que puede crear la conexión del barrio con un horizonte de dimensiones internacionales, más aún, cosmopolitas.

\section{Referencias bibliograficas}

Aricó, José (1980). "Ni cinismo ni utopía", en Revista Controversia. Para el examen de la realidad argentina, $\mathrm{N}^{\circ} 9 / 10$.

Aricó, José (1980b). Marx y América latina. Lima: CEDES.

Aricó, José (1985). "Prólogo", en Labastida Martín del Campo, Julio (coord.), Hegemonía y alternativas políticas en América latina. México: Siglo XXI.

Aricó, José (1986). "Una oportunidad de ponernos al día”, en La Ciudad futura, $\mathrm{N}^{\circ} 2$.

Aricó, José (1990). “¿Hay formas socialistas de resolver la crisis urbana?”, en Punto de vista, $\mathrm{N}^{\circ} 48$.

Aricó, José (1991). "Para abrir un debate amplio y desprejuiciado", en La Vanguardia, $\mathrm{N}^{\circ} 1024$.

Aricó, José (1991b). "Recuperar la memoria de las experiencias comunales: sobre el socialismo municipal", en La Ciudad futura, $\mathrm{N}^{\circ} 28$.

Burgos, Raúl (2004). Los gramscianos argentinos. Cultura y política en la experiencia de Pasado y Presente. Buenos Aires: Siglo XXI.

Vargas, Hugo (ed.) (1979). "Editorial”, Revista Controversia. Para el examen de la realidad argentina, $\mathrm{N}^{\circ}$ 1, octubre 1979, México.

Frondizi, Silvio (2014). La integración mundial, última etapa del capitalismo (y otros escritos). Buenos Aires: Peña Lillo/Continente.

Gramsci, Antonio (2000). Cuadernos de la cárcel. México: Era. 

ISSN 0719-4234 / eISSN 0719-4242

Tarcus, Horacio (1996). El marxismo olvidado en la Argentina: Silvio Frondizi y Milcíades Peña. Buenos Aires: El cielo por asalto.

Wright Mills, Charles (1961). La imaginación sociológica. México: FCE. 